\title{
Simulation of jet-flow solid fraction during spray forming
}

\author{
Zi-qiang $P i^{1)}$, Xin Lu ${ }^{1)}$, Yuan $W u^{2)}$, Lu-ning Wang ${ }^{1)}$, Cheng-chang Jia ${ }^{1)}$, Xuan-hui $Q u^{1)}$, Wei Zheng ${ }^{3)}$, \\ Li-zhi $\mathrm{Wu}^{3)}$, and Qing-li Shao ${ }^{3)}$ \\ 1) Institute for Advanced Materials and Technology, University of Science and Technology Beijing, Beijing 100083, China \\ 2) State Key Laboratory for Advanced Metals and Materials, University of Science and Technology Beijing, Beijing 100083, China \\ 3) Heye Special Steel Co., Ltd., Shijiazhuang 052165, China \\ (Received: 1 November 2016; revised: 20 January 2017; accepted: 15 February 2017)
}

\begin{abstract}
A numerical model was developed to simulate the jet-flow solid fraction of W18Cr4V high-speed steel during spray forming. The whole model comprises two submodels: one is an individual droplet model, which describes the motion and thermal behaviors of individual droplets on the basis of Newton's laws of motion and the convection heat transfer mechanism; the other is a droplet distribution model, which is used to calculate the droplet size distribution. After being verified, the model was used to analyze the effects of parameters, including the initial gas velocity, deposition distance, superheat degree, and the ratio of gas-to-metal mass flow rates, on the jet-flow solid fraction. Finally, an equation to predict the jet-flow solid fraction directly and conveniently according to the parameters was presented. The values predicted by the equation show good agreement with those calculated by the numerical model.
\end{abstract}

Keywords: modeling; steel; spray forming; solid fraction

\section{Introduction}

As a novel rapid solidification and near-net-shape technique, spray forming has various advantages, such as elimination of macrosegregation compared to casting technology and fewer process steps compared to conventional powder metallurgy. As a result, spray forming has received tremendous attention in the materials manufacturing field. Mesquita and Barbosa [1] reported that spray-formed AISI M3:2 high-speed steel has a finer and more uniform microstructure and greater isotropy than conventionally cast steel. Schulz et al. [2] reported that laboratory-scale spray-formed high-alloy steels were competitive with conventional products in terms of toughness and strength. Zhang et al. [3] observed that, in the case of spray-formed T15 high-speed steel, $\mathrm{M}_{6} \mathrm{C}$ and $\mathrm{MC}$ carbides were spherically refined and uniformly distributed after thermomechanical processing. In recent years, spray forming has been widely used to design and prepare various high-performance alloys. For instance, FGH95 superalloy [4], AA7050 alloy [5], Al-50Si (wt\%) alloy [6], and $\mathrm{Cu}-11.85 \mathrm{Al}-3.2 \mathrm{Ni}-3 \mathrm{Mn}(\mathrm{wt} \%)$ shape mem- ory alloy [7] exhibit fine and uniform microstructures as well as good mechanical properties when prepared by spray forming.

During the spray-forming process, the surface solid fraction of the deposited preform is a key factor determining the properties and qualities of the products. In the case of an excessively high solid fraction, high density of the deposited preform can hardly be achieved; by contrast, the spray yield will be reduced in the case of a low solid fraction. However, the surface solid faction of the deposit is very difficult to measure directly. Given that the surface solid fraction is determined by the droplets' cooling process, an individual droplet's solid fraction and the distribution of the droplet size are usually combined and simulated to reflect the surface fraction. Thus far, research on the simulation technology of spray forming has led to substantial advancements. Grant et al. [8] established an individual droplet model to investigate the motion and thermal history of a droplet. Using this model, the influential parameters for spray forming, including the droplet size distribution, initial axial gas velocity, melt mass flow rate, melt superheat, and the alloy 
composition, were investigated [9]. On the basis of the results of these investigations, Grant and Cantor [10] analyzed complex equations to give an approximate expression for the spray solid fraction as a function of process parameters. Mi and Grant [11-12] later modified the model and presented a companion model to simulate the heat flow and solidification of $\mathrm{Ni}$ superalloy rings during spray forming. Cai and Lavernia [13-14] developed a porosity model based on droplet thermal history, particle-packing theory, and flow mechanics to estimate the porosity in a deposited IN718 alloy billet. Kang and Chang [15] established a theoretical model to predict the shape of the billet and the effects of the most dominant processing conditions. In addition, Hattel et al. [16] developed an integrated model to predict the shape of a Gaussian or a billet deposit. Cui and Schulz [17] developed a shape model for clad deposits. Mi et al. [18] developed an integrated, multiphysics numerical model that consisted of an atomization model, a droplet spray model, a droplet deposition model, and a porosity model. Jiang et al. [19] reviewed the physical models and advanced methods used in simulations of gas-liquid two-phase jet flows during atomization and spray processes. A gas jet superposition model, coupled with a series of newly developed numerical-parameter-independent submodels, including the radius-of-influence collision model, mean collision time model, and the polar interpolation model, was proposed by Gao et al. [20] for computing group-hole nozzle sprays. In another work, Du and Wei [21] established a 3D numerical model of flow and heat-transfer to analyze the appropriate forming conditions.

However, few simulation studies concerning spray-formed high-speed steel have been reported. Therefore, the previous simulation results cannot be directly applied to the spray forming of high-speed steels. Additionally, few of the previously reported simulation results have been verified in an industrial production process.

In this paper, the motion and heat-transfer mechanisms of W18Cr4V high-speed steel droplets during spray forming were investigated and the optimal production parameters were discussed.

\section{Model establishment}

\subsection{Gas motion and cooling behaviors}

The scheme of the spray-forming process is shown in Fig. 1. The axial gas velocity shows an exponential decay with increasing distance and can be described as

$v_{\mathrm{g}}=v_{\mathrm{gi}} \exp \left(-\frac{Z}{\lambda_{v}}\right)$

where $v_{\mathrm{g}}$ is the gas velocity, $v_{\mathrm{gi}}$ is the gas velocity at the exit from the atomizer or the initial gas velocity, $Z$ is the deposition distance, and $\lambda_{v}=a_{0} v_{\mathrm{gi}}^{n}$ is the exponential decay coefficient, where $a_{0}=3.04 \times 10^{-4} \mathrm{~m}^{-0.24} \mathrm{~s}^{1.24}$ and $n=1.24$ [8].

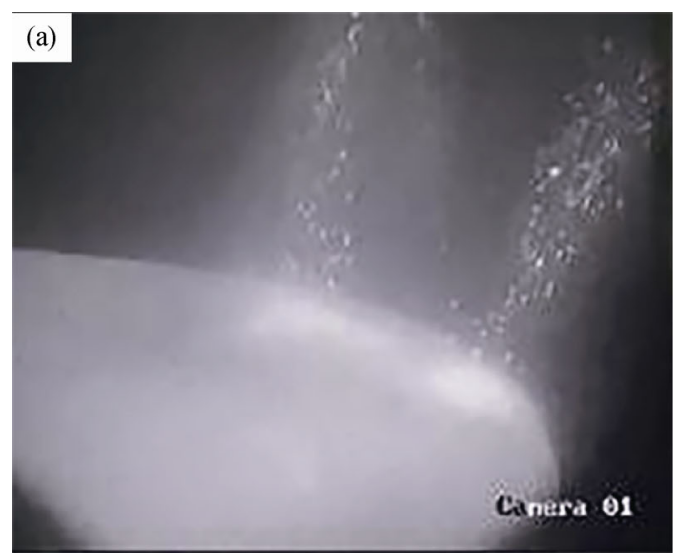

(b)

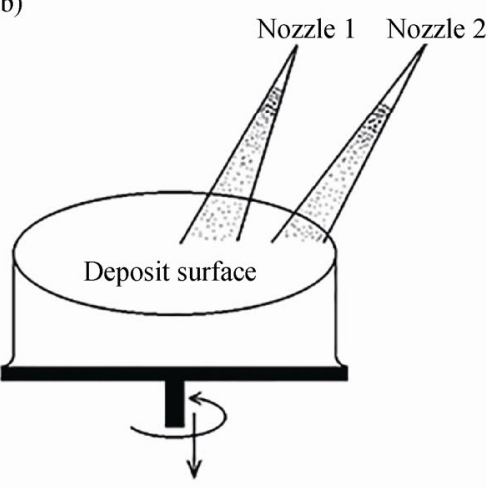

Fig. 1. Live-action (a) and schematic (b) of the spray-forming process.

The gas temperature $T_{\mathrm{g}}$ increases exponentially from an initial temperature $T_{\mathrm{gi}}=25^{\circ} \mathrm{C}$ at the atomizer exit to a final temperature $T_{\mathrm{gf}}=75^{\circ} \mathrm{C}$ on the surface of the deposited preform [8]:

$T_{\mathrm{g}}=T_{\mathrm{gf}}-\left(T_{\mathrm{gf}}-T_{\mathrm{gi}}\right) \exp \left(-\frac{Z}{\lambda_{T}}\right)$

where $\lambda_{T}$ is a constant and equals $0.1 \mathrm{~m}$.

\subsection{Droplet motion and cooling behaviors}

\subsubsection{Droplet motion behaviors}

Droplets were considered to be essentially stationary. A drag force, which results from the difference in velocity between the droplets and the atomizing gas, can cause the droplets to accelerate or decelerate. The acceleration of the droplets is expressed on the basis of Newton's second law [22]: 
$\frac{\mathrm{d} v_{\mathrm{d}}}{\mathrm{d} t}=\left(1-\frac{\rho_{\mathrm{g}}}{\rho_{\mathrm{d}}}\right) \mathrm{g}+\frac{3 \rho_{\mathrm{g}} C_{\mathrm{D}}\left|v_{\mathrm{d}}-v_{\mathrm{g}}\right|\left(v_{\mathrm{g}}-v_{\mathrm{d}}\right)}{4 d \rho_{\mathrm{d}}}$

where $\rho_{\mathrm{d}}$ and $v_{\mathrm{d}}$ are the droplet density and droplet velocity, respectively, $\rho_{\mathrm{g}}$ and $v_{\mathrm{g}}$ are the gas density and velocity, respectively, $t$ is droplet flight time, $\mathrm{g}$ is the acceleration of gravity, $d$ is the droplet diameter, and $C_{\mathrm{D}}$ is the drag coefficient, which can be obtained by

$C_{\mathrm{D}}=0.28+\frac{6}{\sqrt{R e}}+\frac{21}{R e}$

where $\operatorname{Re}=\left(\rho_{\mathrm{g}} d\left|v_{\mathrm{d}}-v_{\mathrm{g}}\right|\right) / \mu_{\mathrm{g}}$ is the Reynolds number $(0.1 \leq \operatorname{Re}$ $\leq 4000)$ and $\mu_{\mathrm{g}}$ is the gas viscosity.

\subsubsection{Droplet cooling behaviors}

The typical $\mathrm{W} 18 \mathrm{Cr} 4 \mathrm{~V}$ droplet cooling process comprises four stages. First, the molten droplets cool. Because of a lack of heterogeneous nucleation sites, droplets cool rapidly below the alloy liquidus temperature $T_{1}$ from the initial droplet temperature $T_{\mathrm{di}}=T_{1}+\Delta T$ until reaching the nucleation temperature $T_{\mathrm{n}}$, where $\Delta T$ is the superheat degree. Thus, the supercooled droplets gain sufficient energy for nucleation. In this stage, the droplet temperature is calculated by

$\frac{\mathrm{d} T_{\mathrm{d}}}{\mathrm{d} t}=-\frac{6 h\left(T_{\mathrm{d}}-T_{\mathrm{g}}\right)}{C_{\mathrm{d}} \rho_{\mathrm{l}} d}$

where $T_{\mathrm{d}}$ and $C_{\mathrm{d}}$ are the temperature and specific heat of individual droplets, respectively, $\rho_{1}$ is the density of the melt metal, $T_{\mathrm{g}}$ is the temperature of gas, and $h$ is the heat-transfer coefficient, which is given by

$h=\frac{k_{\mathrm{g}}\left(2.0+0.6 \operatorname{Re}^{0.5} \operatorname{Pr}^{0.33}\right)}{d}$

where $k_{\mathrm{g}}$ is the thermal conductivity of gas, $\operatorname{Pr}=C_{\mathrm{g}} \mu_{\mathrm{g}} / k_{\mathrm{g}}$ is the Prandtl number of gas, and $C_{\mathrm{g}}$ is the specific heat of gas.

Second, nucleation and recoalescence occur. At the beginning of nucleation, the high undercooling degree, which provides a strong driving force, leads to rapid nucleation. During the nucleation, the latent heat is released within an extremely short period. As a consequence, the droplet temperature rapidly increases to the liquidus temperature. The frequency of heterogeneous nucleation is described as Eq. (7) [23]:

$I=10^{40} \exp \left[-\frac{16 \pi}{3 k_{\mathrm{B}} T_{\mathrm{d}}} \frac{\sigma_{\mathrm{SL}}^{3} T_{1}^{2} F(\theta)}{\rho_{\mathrm{d}}^{2} \Delta H_{\mathrm{f}}^{2} \Delta T_{\mathrm{d}}^{2}}\right]$

where $\sigma_{\mathrm{SL}}$ is the interfacial energy between the solid and the liquid interface, $\theta$ is the wetting angle of a nucleus on the wheel surface, $\Delta T_{\mathrm{d}}$ is the undercooling degree, $k_{\mathrm{B}}$ is the Boltzmann constant, and $\Delta H_{\mathrm{f}}$ is the latent heat per unit mass. The catalytic efficiency of heterogeneous nucleation $F(\theta)$ is given by [8]

$F(\theta)=\frac{1}{4}\left(2-3 \cos \theta+\cos ^{3} \theta\right)=a_{1}+\frac{a_{2}}{d}$

where $a_{1}=-5.025 \times 10^{-3}$ and $a_{2}=1.005 \mu \mathrm{m}$ [24-25].

The droplet solid fraction $f_{\mathrm{d}}=\Delta T_{\mathrm{d}} C_{1} / \Delta H_{\mathrm{f}}$, where $C_{1}$ is specific heat of the melt metal.

Third, the phase transition occurs. After recoalescence, the undercooling degree of droplets decreases; hence, the solidification rate slows. When the latent heat cannot afford the heat loss through convection, the droplet temperature decreases again. Until the melting point $T_{\mathrm{m}}$ is reached, the equivalent specific heat $C_{\text {equ }}=C_{\mathrm{d}}+\Delta H_{\mathrm{f}} /\left(T_{1}-T_{\mathrm{m}}\right)$ is used to replace the latent heat; thus, the droplet temperature can be described as

$\frac{\mathrm{d} T_{\mathrm{d}}}{\mathrm{d} t}=-\frac{6 h\left(T_{\mathrm{d}}-T_{\mathrm{g}}\right)}{\rho_{\mathrm{d}} C_{\text {equ }} d}$

The change of the droplet solid fraction in phase transition can be calculated by the Scheil equation:

$f_{\mathrm{d}}=1-\left(\frac{T_{\mathrm{m}}-T_{\mathrm{d}}}{T_{\mathrm{m}}-T_{1}}\right)^{\frac{1}{k_{0}-1}}$

where $k_{0}$ is the equilibrium partition coefficient.

Fourth, the solid droplets cool. Solidification is completed when the melting temperature $T_{\mathrm{m}}$ is reached, then the full solid-state droplets continue cooling. The temperature can be described by

$\frac{\mathrm{d} T_{\mathrm{d}}}{\mathrm{d} t}=-\frac{6 h\left(T_{\mathrm{d}}-T_{\mathrm{g}}\right)}{\rho_{\mathrm{d}} C_{\mathrm{d}} d}$

\subsection{Jet-flow solid fraction}

The jet-flow solid fraction $f_{\mathrm{s}}$ is calculated by combining the individual droplets solid fraction and the droplet size distribution.

$f_{\mathrm{s}}=\int_{0}^{\infty} P\left(d_{i}\right) \cdot f\left(d_{i}\right) \mathrm{d} \ln d$

where $P\left(d_{i}\right)$ is the droplet probability density with diameter $d_{i}$ and is given by Eq. (13) [26]:

$P\left(d_{i}\right)=\frac{1}{\sqrt{2 \pi} \ln \sigma} \exp \left[-\frac{\left(\ln d_{i}-\ln d_{50}\right)^{2}}{2 \ln ^{2} \sigma}\right]$

where $\sigma=\left(d_{50} / 13\right)^{1 / 3}$ is the geometric standard deviation and $d_{50}$ is the average diameter, which can be calculated by Eq. (14), as proposed by Lubanska [27].

$d_{50}=D \cdot \beta \sqrt{\frac{\kappa_{\mathrm{m}} \sigma_{\mathrm{m}}}{\kappa_{\mathrm{g}} v_{\mathrm{g}}^{2} D}\left(1+\frac{1}{R}\right)}$

where $D$ is the diameter of the molten metal nozzle, $\beta$ is a 
constant and equals $40, \kappa_{\mathrm{m}}$ is the kinematic viscosity of the molten metal, $\kappa_{\mathrm{g}}$ is the kinematic viscosity of the gas, $R$ is the ratio of gas-to-metal mass flow rates, and $\sigma_{\mathrm{m}}$ is the surface tension of the molten metal.

\section{Results and discussion}

\subsection{Motion and thermal behaviors of individual droplets}

The values of thermophysical properties of $\mathrm{N}_{2}$ atomizing gas and $\mathrm{W} 18 \mathrm{Cr} 4 \mathrm{~V}$ high-speed steel used in the calculation are listed in Table 1. The velocities, heat-transfer coefficients, temperatures, and solid fractions of individual droplets are calculated from the model described in the paper; the results are shown in Figs. 2-5 for droplet sizes of 20 to $200 \mu \mathrm{m}$, an initial gas velocity of $300 \mathrm{~m} / \mathrm{s}$, a deposition distance of $0.5 \mathrm{~m}$, a superheat degree of $100 \mathrm{~K}$, and a ratio of gas-to-metal mass flow rates of 0.55 .

As shown in Fig. 2, the droplet velocity with different diameters increases rapidly to a maximum value and then decreases gradually. The droplet velocity is strongly affected by the droplet diameter. The smaller droplets show sharp acceleration or deceleration; however, the larger ones gradually accelerate and decelerate slowly due to their larger inertia. For instance, droplets with a diameter of $20 \mu \mathrm{m}$ reach the maximum velocity of $205 \mathrm{~m} / \mathrm{s}$ at a distance of $0.13 \mathrm{~m}$, whereas the $130-\mu \mathrm{m}$ ones reach the maximum velocity of $110 \mathrm{~m} / \mathrm{s}$ at a distance of $0.34 \mathrm{~m}$.

Table 1. Thermophysical properties of $\mathrm{N}_{2}$ atomizing gas and W18Cr4V high-speed steel

\begin{tabular}{cl}
\hline Nitrogen gas [23] & \multicolumn{1}{c}{$\mathrm{W} 18 \mathrm{Cr} 4 \mathrm{~V}$} \\
\hline$\rho_{\mathrm{g}}=1.1616 \mathrm{~kg} \cdot \mathrm{m}^{-3}$ & $\rho_{\mathrm{d}}=8700 \mathrm{~kg} \cdot \mathrm{m}^{-3}$ \\
$\mu_{\mathrm{g}}=1.873 \times 10^{-5} \mathrm{~Pa} \cdot \mathrm{s}$ & $\rho_{1}=8100 \mathrm{~kg} \cdot \mathrm{m}^{-3}$ \\
$k_{\mathrm{g}}=0.026 \mathrm{~W} \cdot \mathrm{m}^{-1} \cdot \mathrm{K}^{-1}$ & $C_{\mathrm{d}}=686.67 \mathrm{~J} \cdot \mathrm{kg}^{-1} \cdot \mathrm{K}^{-1}$ \\
$C_{\mathrm{g}}=1043.21 \mathrm{~J} \cdot \mathrm{kg}^{-1} \cdot \mathrm{K}^{-1}$ & $C_{1}=816.47 \mathrm{~J} \cdot \mathrm{kg}^{-1} \cdot \mathrm{K}^{-1}$ \\
- & $T_{\mathrm{m}}=1613.15 \mathrm{~K}$ \\
- & $T_{1}=1751.15 \mathrm{~K}$ \\
- & $\Delta H_{\mathrm{f}}=242 \mathrm{~J} \cdot \mathrm{kg}^{-1}$ \\
- & $\sigma_{\mathrm{SL}}=1.5 \mathrm{~J} \cdot \mathrm{m}^{-2}$ \\
\hline
\end{tabular}

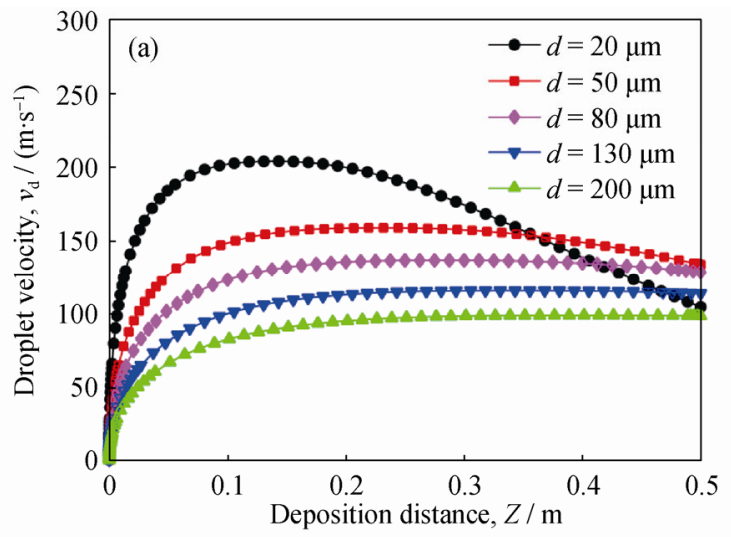

(b)

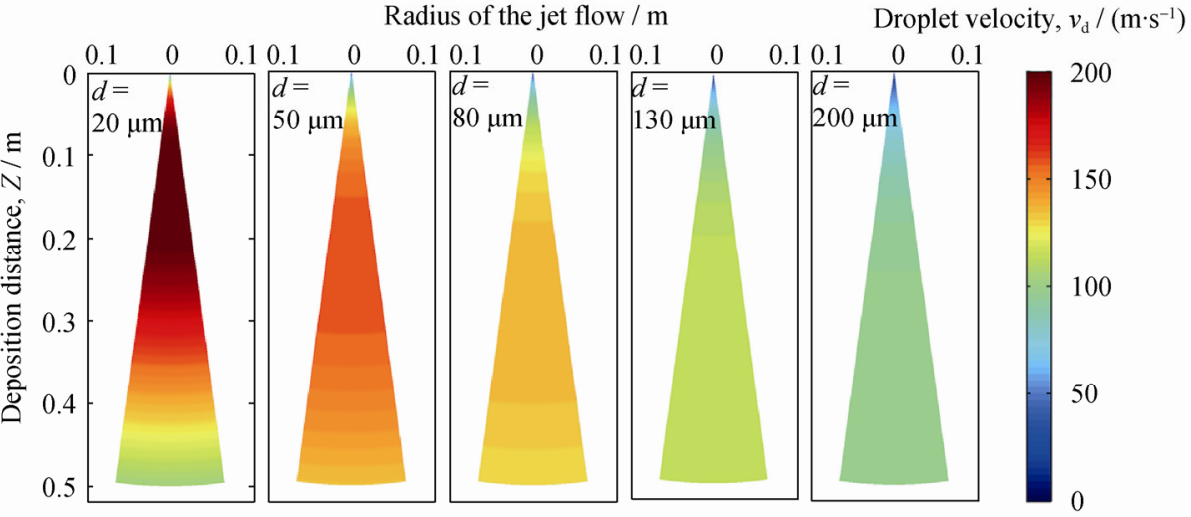

Fig. 2. Single droplet motion behavior $\left(v_{\mathrm{gi}}=300 \mathrm{~m} / \mathrm{s}, \Delta T=100 \mathrm{~K}, \boldsymbol{R}=\mathbf{0 . 5 5}\right.$ ): (a) change of a single droplet velocity vs. deposition distance; (b) velocity distribution of a single droplet in the jet flow.

Fig. 3 shows the heat-transfer coefficient as a function of deposition distance. The initial heat-transfer coeffi- cients of all the droplets are extremely high because of the large relative velocity between the droplets and the 
gas. The gas then accelerates the droplets sharply, which reduces the relative velocity; as a consequence, the heat-transfer coefficients decrease rapidly. When the droplet velocity is equal to the gas velocity, the heat-transfer coefficients momentarily decrease to a minimum value. Subsequently, the heat-transfer coefficients again increase because the decay of the gas velocity increases the relative velocity between the droplets and the gas molecules.

Fig. 4 shows droplet temperature as a function of deposition distance. Four different cooling stages are observed, including rapid cooling of the melt droplets, nucleation and recoalescence, phase transition, and cooling of the solid droplets. The $20-\mu \mathrm{m}$ droplets are clearly observed to undergo four cooling stages. Because smaller droplets favor higher cooling rates, the smaller droplets nucleate at a shorter distance and have a lower temperature when they reach the deposition surface.

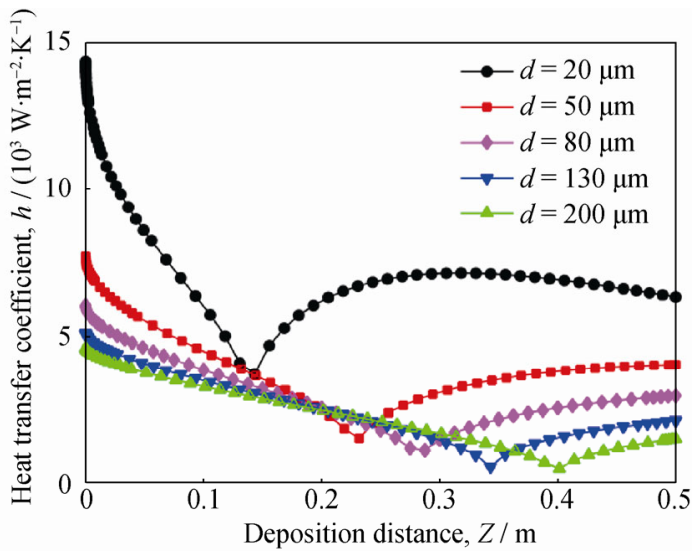

Fig. 3. Heat-transfer coefficient of a single droplet varying with deposition distance $\left(v_{\mathrm{gi}}=300 \mathrm{~m} / \mathrm{s}, \Delta T=100 \mathrm{~K}, R=0.55\right)$.
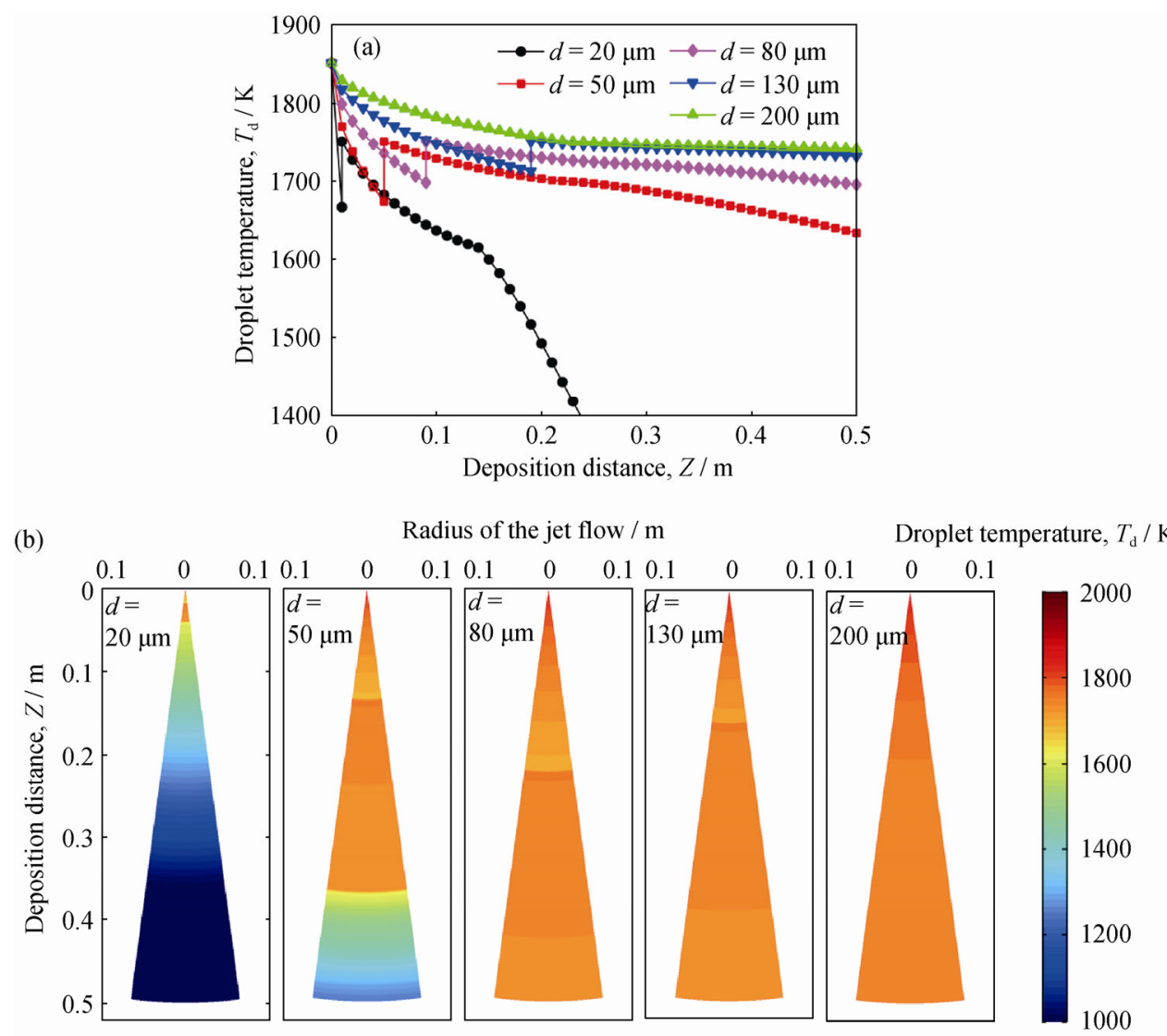

Fig. 4. Single droplet thermal behavior $\left(v_{\mathrm{gi}}=300 \mathrm{~m} / \mathrm{s}, \Delta T=100 \mathrm{~K}, \boldsymbol{R}=\mathbf{0 . 5 5}\right)$ : (a) temperature of a single droplet varying with deposition distance; (b) temperature distributions of a single droplet in the jet flow.

Fig. 5 shows the solid fraction of individual droplets as a function of deposition distance. This figure shows that the droplet solid fraction decreases with increasing droplet diameter. At a certain deposition distance of $0.5 \mathrm{~m}$, droplets with a diameter of $20 \mu \mathrm{m}$ are fully solidified, whereas drop- lets with a diameter of $50 \mu \mathrm{m}$ or greater are semisolid. Additionally, with decreasing droplet diameter, the cooling rate increases; as a result, the distance required for nucleation and recoalescence decreases and the solid fraction achieved during nucleation and recoalescence increases. 


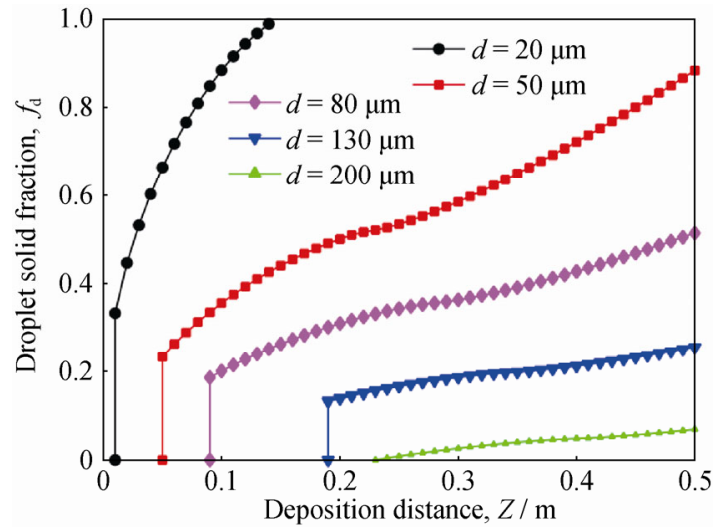

Fig. 5. Variation of the solid fraction of a single droplet as a function of deposition distance $\left(v_{\mathrm{gi}}=300 \mathrm{~m} / \mathrm{s}, \Delta T=100 \mathrm{~K}, R=0.55\right)$.
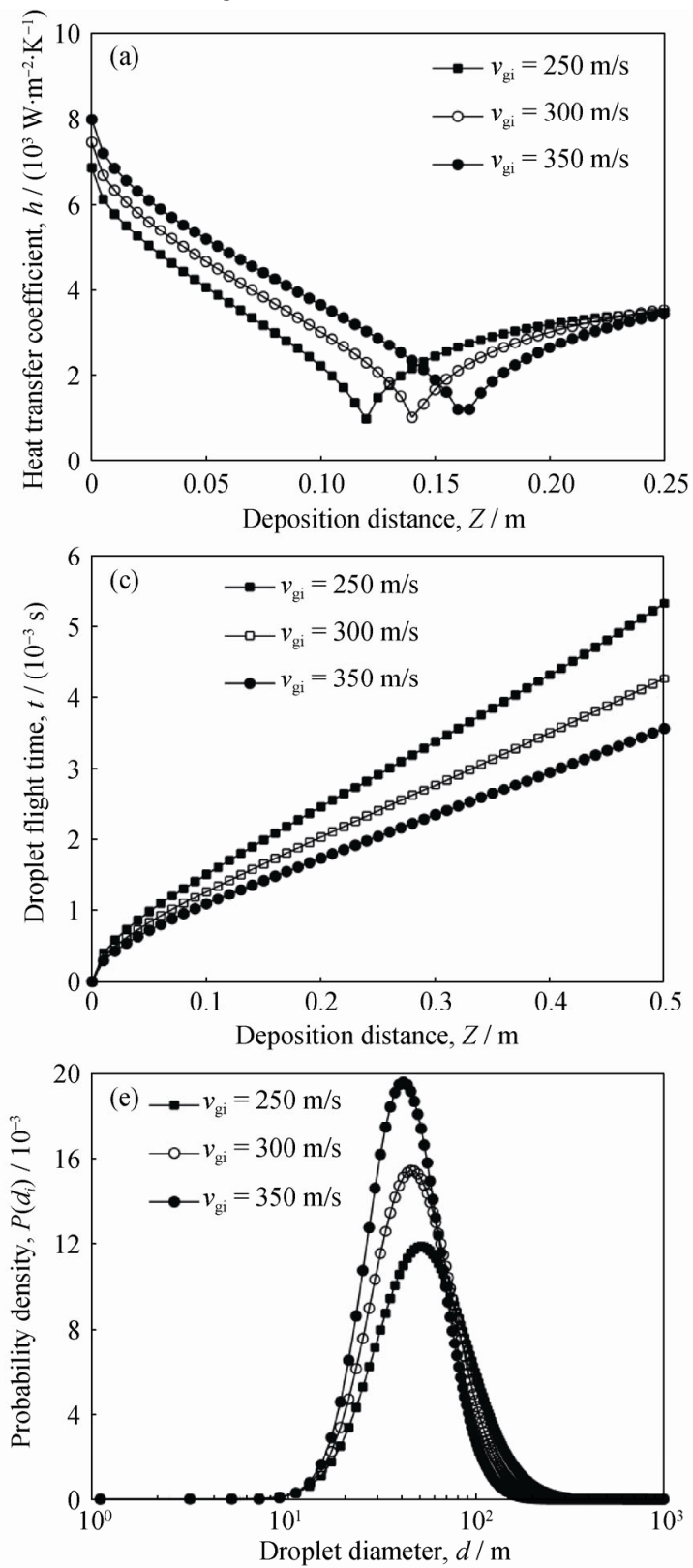

\subsection{Motion and thermal behaviors of jet flow}

The jet-flow solid fraction was calculated by combining the solid fraction of individual droplets and the droplet size distribution. The effects of initial gas velocity, deposition distance, superheat, and the ratio of gas-to-metal mass flow rates were investigated.

Fig. 6 shows the heat transfer coefficient, velocity, flight time, temperature, and solid fraction of $80-\mu \mathrm{m}$ droplets as a function of the deposition distance, with the same superheat degree of $100 \mathrm{~K}$ and the same ratio of gas-to-metal mass flow rate of 0.55 , but with an initial gas velocity increasing from 250 to $350 \mathrm{~m} / \mathrm{s}$.
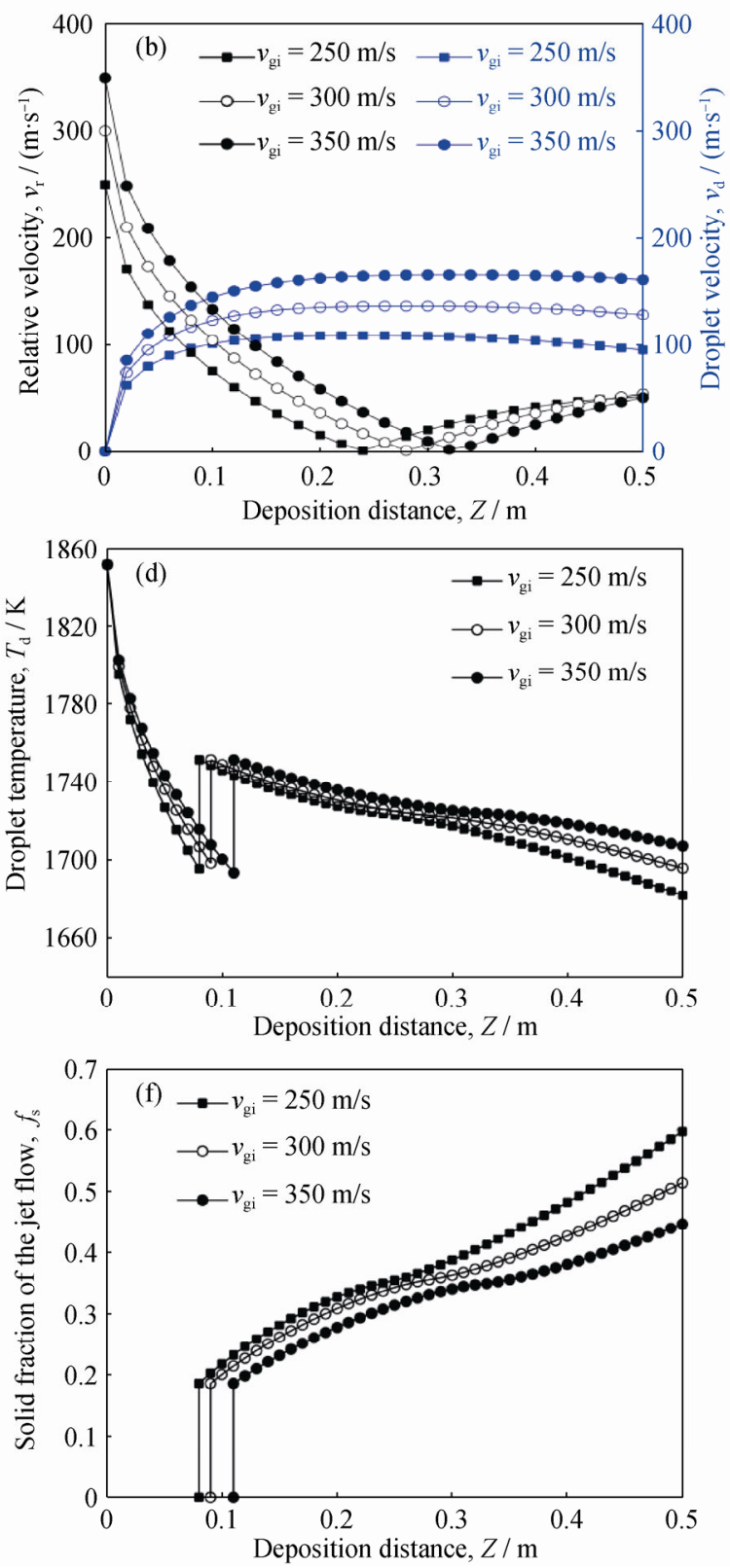

Fig. 6. Variations of the parameters of droplets with different initial velocities of gas: (a) heat transfer coefficient; (b) velocity; (c) time; (d) temperature; (e) size distribution of droplets; (f) solid fraction. 
As depicted in Fig. 6(a), the heat transfer coefficient increases with increasing initial gas velocity. Moreover, for droplets with a larger initial gas velocity, the point where the heat transfer coefficient decreases to the minimum value is farther from the nozzle than the corresponding point for droplets with a smaller initial gas velocity; the mean heat transfer coefficient is also evidently larger.

The acceleration of droplets depends on the gas; therefore, a larger initial gas velocity results in a larger droplet velocity, as shown in Fig. 6(b). Additionally, we observed that the relative velocity between droplets and gas decreases to 0 $\mathrm{m} / \mathrm{s}$ at a point and then increases. For droplets with a larger initial gas velocity, the $0 \mathrm{~m} / \mathrm{s}$ point is farther from the nozzle than the corresponding points for droplets with a smaller initial gas velocity. Compared with Fig. 6(a), the relative velocity and the heat transfer coefficient have a similar variation trend because the latter has a positive relationship with the former, as shown in Eq. (5).

Fig. 6(c) shows the flight time as a function of deposition distance. This figure clearly shows that the increase in initial gas velocity will shorten the droplet flight time. For example, the flight time over a $0.5-\mathrm{m}$ deposition distance decreases from 0.0052 to $0.0035 \mathrm{~s}$ when the initial gas velocity increases from 250 to $350 \mathrm{~m} / \mathrm{s}$.
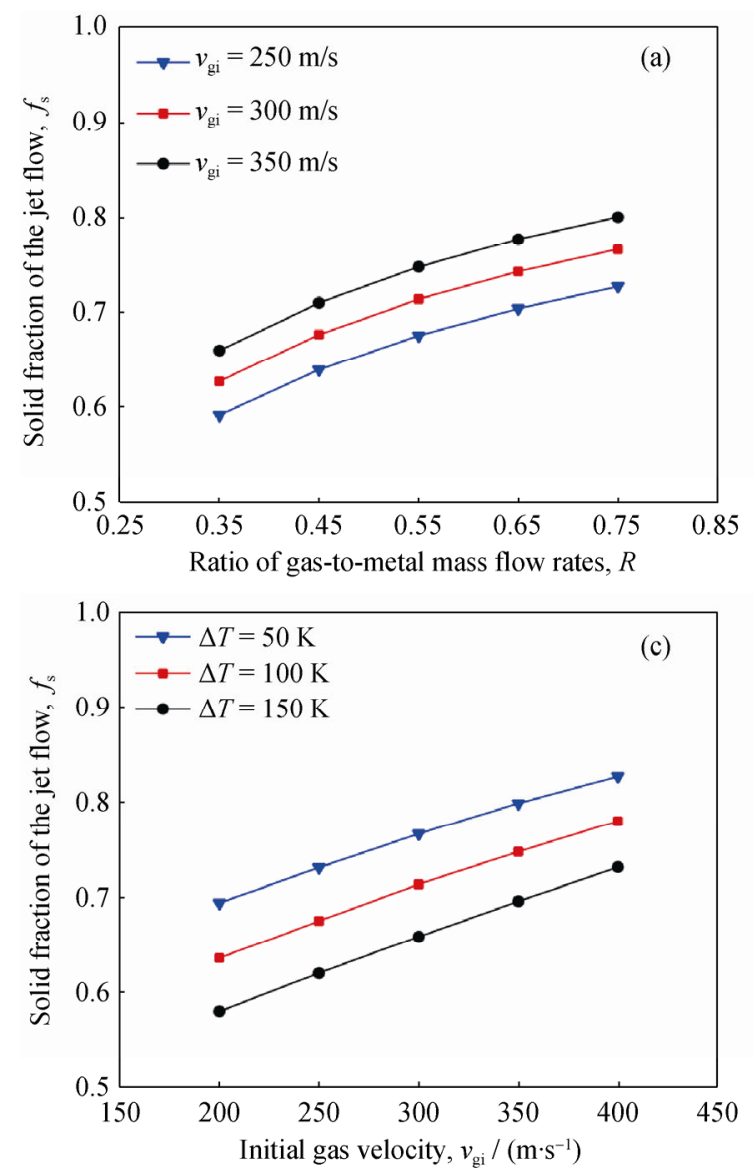

The droplet temperature is determined by its cooling rate and time. We concluded that the mean heat transfer coefficient increases with increasing gas velocity, as shown in Fig. 6(a). Consequently, the cooling rate also increases. However, droplets will require less time to reach the surface of the deposit, as shown in Fig. 6(c). The result of these two antagonistic factors is that the droplet temperature with a larger initial gas velocity is slightly higher compared to that with a lower initial gas velocity; consequently, the solid fraction of droplets is smaller, as shown in Figs. 6(d) and 6(f), respectively. Fig. 6(e) shows that the increase in gas velocity causes an increase in the percentage of smaller droplets because the gas has more energy to atomize the molten metal better.

On the basis of the analysis for the parameters how to affect the solid fraction of individual droplets, the variations in jet-flow solid fraction as functions of the parameters were investigated. Fig. 7(a) shows the variation of jet-flow solid fraction with the deposition distances of $0.4,0.5$, and $0.6 \mathrm{~m}$ in the range of initial gas velocities from 200 to $400 \mathrm{~m} / \mathrm{s}$ at $50 \mathrm{~m} / \mathrm{s}$ intervals, a gas-to-metal mass flow rate ratio of 0.55 , and a superheat degree of $100 \mathrm{~K}$. The jet-flow solid fraction increases linearly with increasing initial gas velocity. This behavior is attributable to two aspects: (1) a decrease in solid

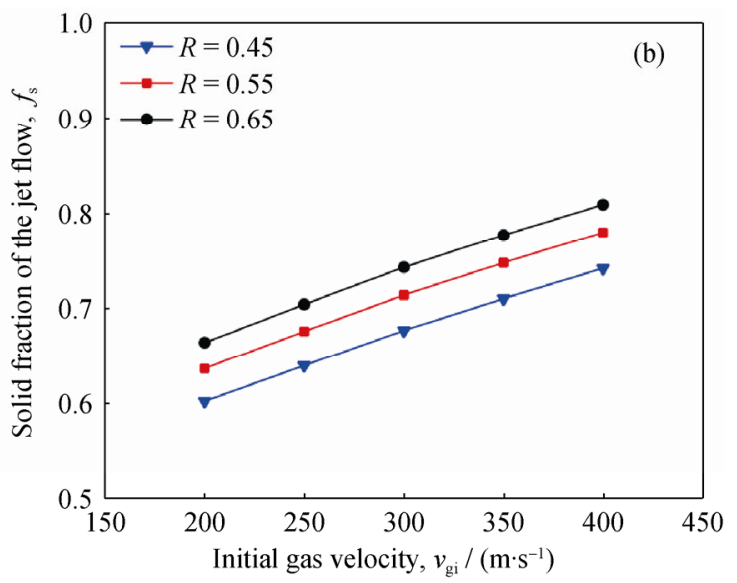

Fig. 7. Variations of the jet-flow solid fraction with different parameters: (a) initial gas velocity; (b) ratio of gas-to-metal mass flow rates; (c) superheat degree. 
fraction of individual droplets, as shown in Fig. 3(f), which decreases the jet-flow solid fraction, and (2) a narrower particle size distribution, which has the opposite effect of the first aspect. However, the second aspect has a greater influence; therefore, when the initial gas velocity increases, the jet-flow solid fraction also increases. Fig. 7(b) shows a solid fraction of jet flow as a function of the ratio of the gas-to-metal mass flow rate from 0.35 to 0.75 , with deposition distances of $0.4,0.5$, and $0.6 \mathrm{~m}$, with an initial gas velocity of $300 \mathrm{~m} / \mathrm{s}$, and with a superheat degree of $100 \mathrm{~K}$. When the ratio increases, the droplet size distribution becomes narrower because of the gas having more power to atomize the liquid metal to smaller droplets. Accordingly, the solid fraction of jet flow increases. Fig. 7(c) shows the jet-flow solid fraction as a function of superheat degree from
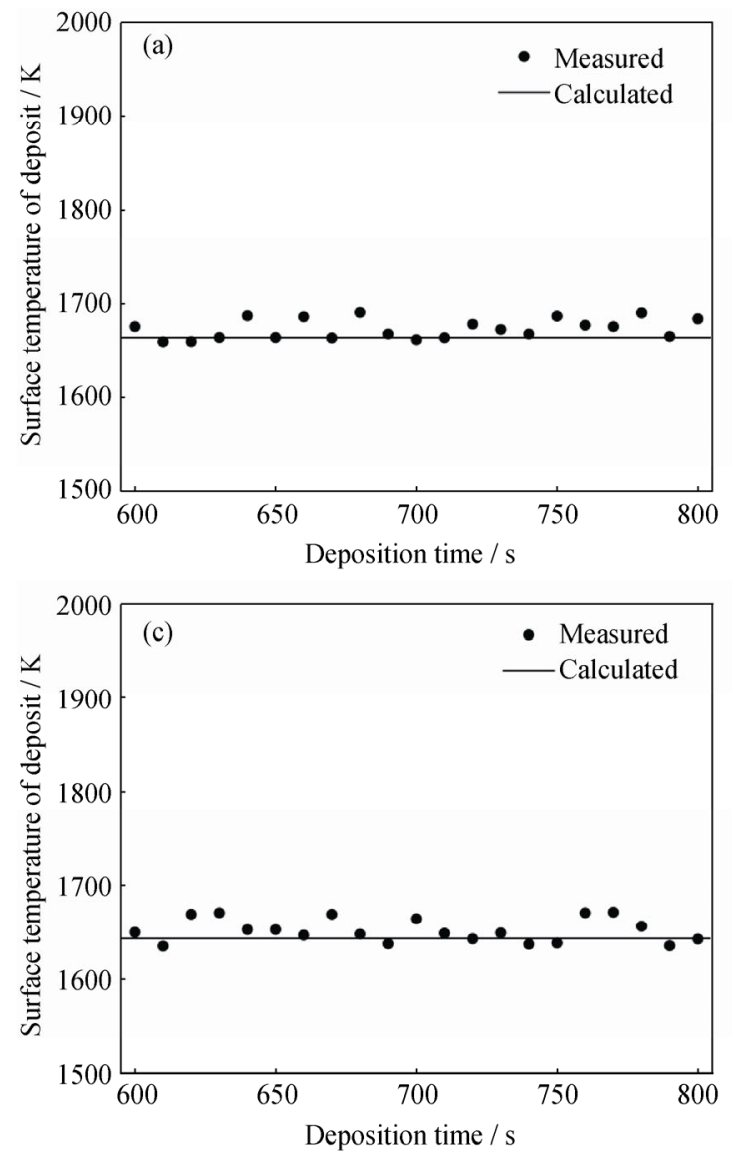

\subsection{Prediction of the jet-flow solid fraction}

During a sufficiently short period of time $\Delta t$, the spray process can be divided into three steps, as shown in Fig. 9. First, the alloy is melted. Second, the molten alloy is atomized into tiny droplets. Third, the droplets crash into the substrate and the billet are formed. In the entire process, the molten alloy has the same weight $m=M \Delta t$ but different temperatures as the newly formed billet, where $m$ is the weight
50 to $250 \mathrm{~K}$, with deposition distances of $0.4,0.5$, and $0.6 \mathrm{~m}$, an initial gas velocity of $300 \mathrm{~m} / \mathrm{s}$, and a gas-to-metal mass flow rate ratio of 0.55 . We concluded that the jet-flow solid fraction decreases with increasing superheat degree because each individual droplet contains more heat compared to those with a lower superheat degree at the same deposition distance.

To verify the model, an infrared thermometer was used to measure the surface temperature of the preform during spray forming, with an initial gas velocity of $300 \mathrm{~m} / \mathrm{s}$, a gas-to-metal mass flow rate ratio of 0.55 , deposition distances of $0.4,0.5$, and $0.6 \mathrm{~m}$, and a superheat degree of 100 K. As exhibited in Figs. 8(a)-8(c), the values calculated by the numerical model are certainly consistent with the measured values; thus, the correctness of the numerical model has been demonstrated.

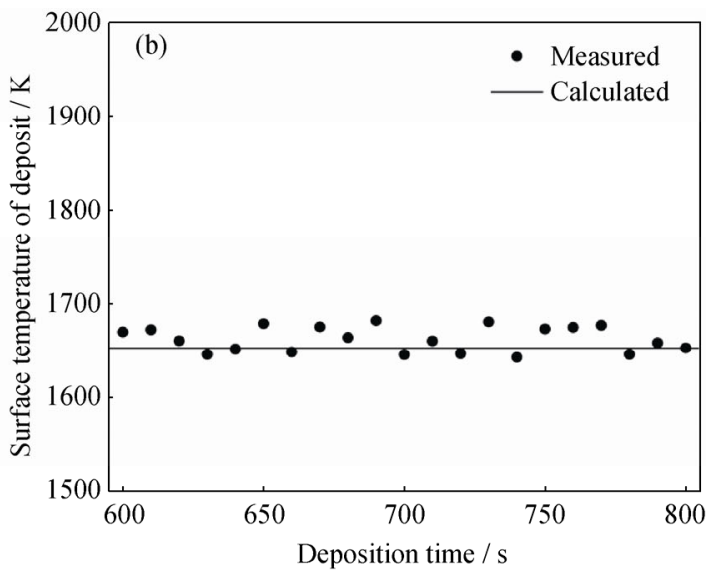

Fig. 8. Comparison between the calculated and the measured values of the preform surface temperature: (a) $Z=0.4 \mathrm{~m}$; (b) $Z=0.5 \mathrm{~m}$; (c) $Z=0.6 \mathrm{~m}$.

of the alloy depositing on the substrate during the period of time $\Delta t$ and $M$ is the mass flow rate of the molten alloy. Thus, as shown by steps 1 to 3 in Fig. 9, the change in heat of the newly deposited alloy $Q_{1}$ can be calculated on the basis of the thermal physical properties of the metals as

$Q_{1}=M \Delta t C_{1} \Delta T+M \Delta t \Delta H_{\mathrm{f}} f_{\mathrm{s}}+M \Delta t C_{\mathrm{d}}\left(T_{1}-T_{\text {surface }}\right)$

where $T_{\text {surface }}$ and $f_{\mathrm{s}}$ are the average temperature and the solid fraction of the jet flow on the surface of the billet, respectively. 


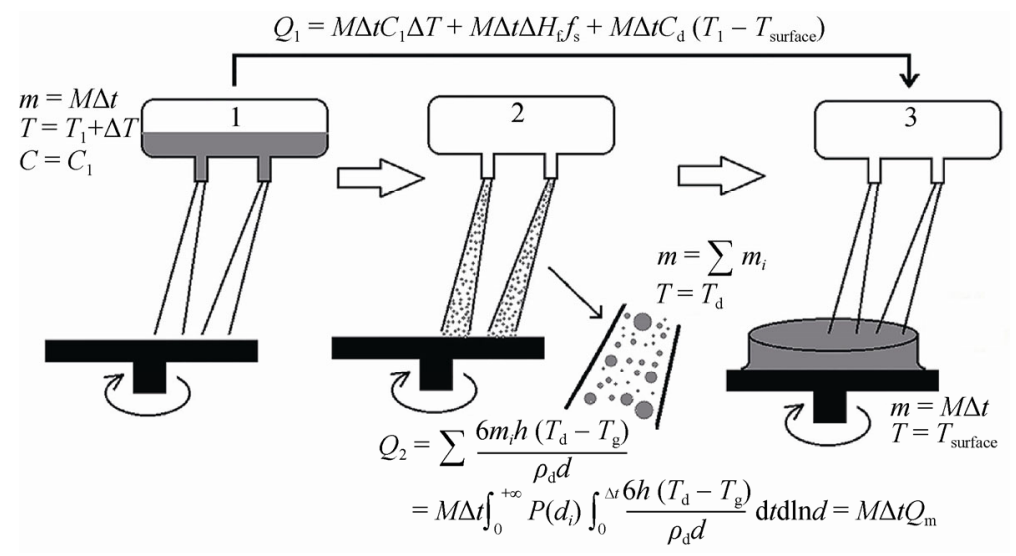

Fig. 9. Sketch of the three steps of the spray forming process during a very short time.

Further analysis reveals that the different temperatures of molten metals and the newly formed billet are mainly caused by $Q_{2}$, which is the heat dissipation of droplets. Therefore, $Q_{2}$ can be calculated by accumulating the heat dissipation of each single droplet as

$$
\begin{aligned}
Q_{2} & =\sum \frac{6 m_{i} h\left(T_{\mathrm{d}}-T_{\mathrm{g}}\right)}{\rho_{\mathrm{d}} d} \\
& =M \Delta t \int_{0}^{+\infty} P\left(d_{i}\right) \int_{0}^{\Delta t} \frac{6 h\left(T_{\mathrm{d}}-T_{\mathrm{g}}\right)}{\rho_{\mathrm{d}} d} \mathrm{~d} t \mathrm{~d} \ln d=M \Delta t Q_{\mathrm{m}}
\end{aligned}
$$

where $Q_{\mathrm{m}}$ is the heat released by the jet flow per unit mass and

$Q_{\mathrm{m}}=\int_{0}^{+\infty} P\left(d_{i}\right) \int_{0}^{\Delta t} \frac{6 h\left(T_{\mathrm{d}}-T_{\mathrm{g}}\right)}{\rho_{\mathrm{d}} d} \mathrm{~d} t \mathrm{~d} \ln d$

Apparently, $Q_{1}=Q_{2}$; thus, $Q_{\mathrm{m}}=C_{\mathrm{l}} \Delta T+\Delta H_{\mathrm{f}} f_{\mathrm{s}}+C_{\mathrm{d}}\left(T_{1}-T_{\text {surface }}\right)$

$Q_{\mathrm{m}}$ is calculated according to the numerical model in this paper with a wide range of parameters; details of the analysis are shown in Figs. 10-12. Specifically, Fig. 10 shows the variation in $Q_{\mathrm{m}}$ as a function of $v_{\mathrm{gi}}^{0.22}$ over the range $200 \leq v_{\mathrm{gi}}$ $\leq 400 \mathrm{~m} / \mathrm{s}$ at $50-\mathrm{m} / \mathrm{s}$ intervals, with different deposition distances $Z$, and with gas-to-metal mass flow rate ratios $R$. The best-fit line is

$Q_{\mathrm{m}}=k v_{\mathrm{gi}}^{0.22}$

where $k$ is the slope of the best-fit line. The values of $k$ and $R$-square were calculated; the results are listed in Table 2. The minimum $R$-square value of 0.9763 means that the points agree well with the best-fit lines.

Fig. 11 shows the variation in $Q_{\mathrm{m}}$ as a function of $R_{19}$ over the range of $0.35 \leq R \leq 0.75$ at 0.1 intervals, with $v_{\mathrm{gi}}=$ 250,300 , and $350 \mathrm{~m} / \mathrm{s}$ and $Z=0.4,0.5$, and $0.6 \mathrm{~m}$. Also, the best-fit lines were calculated and plotted.

$Q_{\mathrm{m}}=k R^{0.19}$ where the value of $k$ and $R$-square are listed in Table 3. The points show reasonable agreement with the best-fit lines.

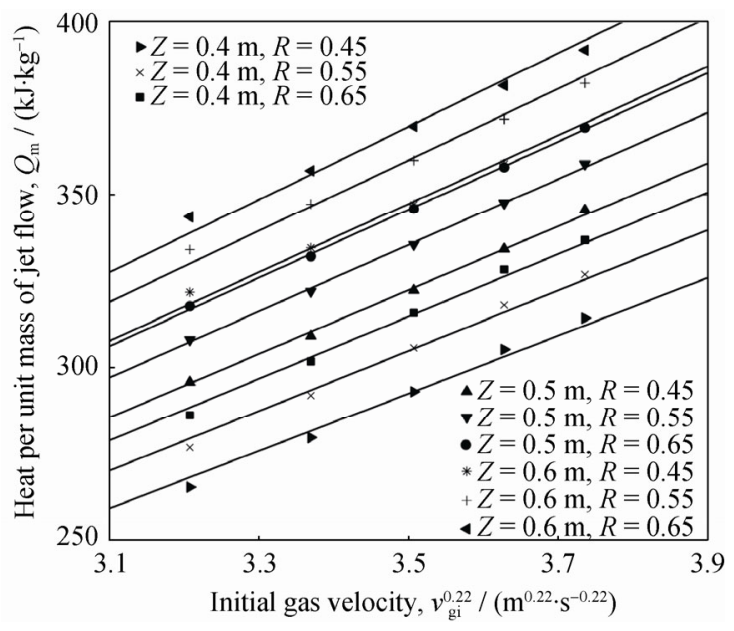

Fig. 10. Variations in $Q_{\mathrm{m}}$ as a function of $v_{\mathrm{gi}}^{0.22}$.

Table 2. Slopes and $R$-square values of the best-fit lines for the variation of jet-flow heat per unit mass $Q_{m}$ with the initial gas velocity $v_{\mathrm{gi}}$

\begin{tabular}{cccc}
\hline$Z / \mathrm{m}$ & $R$ & $k$ & $R$-square \\
\hline \multirow{2}{*}{0.4} & 0.45 & 83.54 & 0.9867 \\
& 0.55 & 87.08 & 0.9904 \\
& 0.65 & 89.91 & 0.9929 \\
\hline \multirow{2}{*}{0.5} & 0.45 & 92.07 & 0.9974 \\
& 0.55 & 95.81 & 0.9984 \\
& 0.65 & 98.73 & 0.9989 \\
\hline \multirow{2}{*}{0.6} & 0.45 & 99.22 & 0.9893 \\
& 0.55 & 102.80 & 0.9843 \\
& 0.65 & 105.60 & 0.9763 \\
\hline
\end{tabular}




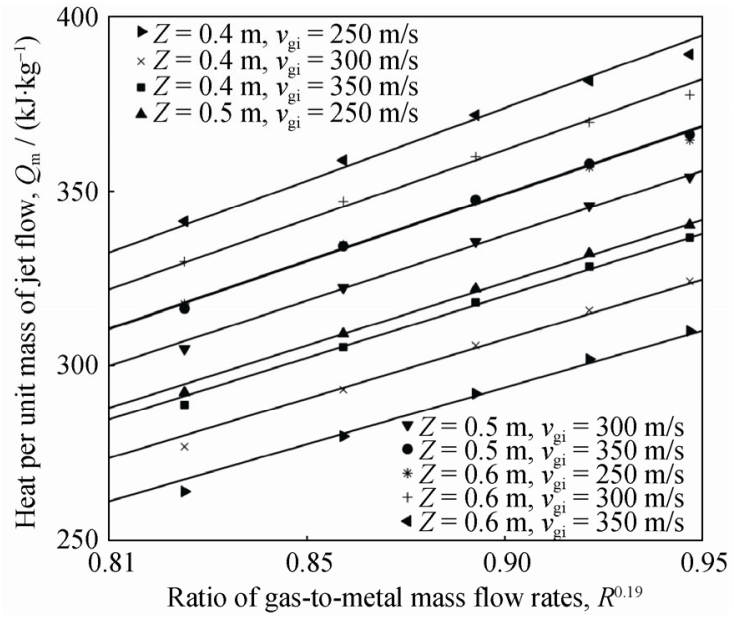

Fig. 11. Variations in $Q_{\mathrm{m}}$ as a function of $R^{0.19}$.

Table 3. Slopes and $R$-square values of the best-fit lines for the variation of jet-flow heat per unit mass $Q_{\mathrm{m}}$ with the gas-to-metal mass flow rate ratio $R$

\begin{tabular}{cccc}
\hline$v_{\mathrm{gi}} /\left(\mathrm{m} \cdot \mathrm{s}^{-1}\right)$ & $Z / \mathrm{m}$ & $k$ & $R$-square \\
\hline \multirow{3}{*}{250} & 0.4 & 326.0 & 0.9888 \\
& 0.5 & 341.4 & 0.9912 \\
& 0.6 & 355.2 & 0.9948 \\
\hline \multirow{3}{*}{300} & 0.4 & 359.4 & 0.9953 \\
& 0.5 & 374.5 & 0.9958 \\
& 0.6 & 388.0 & 0.9964 \\
\hline \multirow{3}{*}{350} & 0.4 & 387.6 & 0.9936 \\
& 0.5 & 401.8 & 0.9902 \\
& 0.6 & 415.0 & 0.9831 \\
\hline
\end{tabular}

Fig. 12 shows the variation in $Q_{\mathrm{m}}$ as a function of $Z^{0.40}$ over the range of $0.3 \leq Z \leq 0.7 \mathrm{~m}$ at $0.1-\mathrm{m}$ intervals, with $v_{\mathrm{gi}}=$ 250,300 , and $350 \mathrm{~m} / \mathrm{s}$ and $R=0.45,0.55$, and 0.65 . In addition, the best-fit lines were also calculated and plotted in Fig. 12.

$Q_{\mathrm{m}}=k Z^{0.40}$

where the value of $k$ and $R$-square are listed in Table 3. The points show good agreement with the best-fit lines.

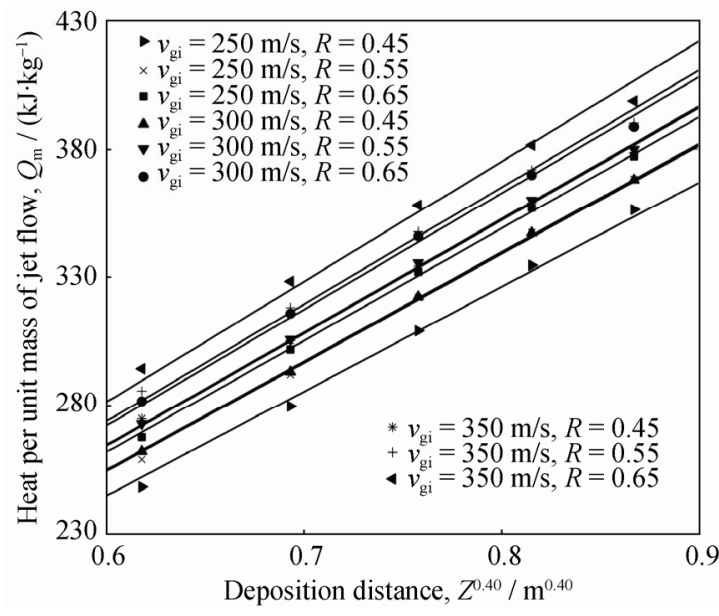

Fig. 12. Variations in $Q_{\mathrm{m}}$ as a function of $Z^{0.40}$.
Table 4. Slopes and $\boldsymbol{R}$-square values for the best-fit lines for the variation of jet-flow heat per unit mass $Q_{\mathrm{m}}$ with the deposition distance $Z$

\begin{tabular}{cccc}
\hline$v_{\mathrm{gi}} /\left(\mathrm{m} \cdot \mathrm{s}^{-1}\right)$ & $R$ & $k$ & $R$-square \\
\hline \multirow{3}{*}{250} & 0.45 & 407.6 & 0.9951 \\
& 0.55 & 423.6 & 0.9977 \\
& 0.65 & 436.0 & 0.9988 \\
\hline \multirow{3}{*}{300} & 0.45 & 424.5 & 0.9996 \\
& 0.55 & 440.7 & 0.9989 \\
& 0.65 & 453.3 & 0.9961 \\
\hline \multirow{2}{*}{350} & 0.45 & 440.0 & 0.9975 \\
& 0.55 & 456.2 & 0.9930 \\
& 0.65 & 468.8 & 0.9855 \\
\hline
\end{tabular}

As a consequence, a relatively simple equation can be obtained from Eqs. (19), (20), and (21):

$Q_{\mathrm{m}}=A v_{\mathrm{gi}}^{0.22} R^{0.19} Z^{0.40}$

where $A$ is a constant. Substituting all the points in Figs. 5(a)-5(c) into Eq. (22) gives the best-fit value $A=140.8$ $\mathrm{m}^{-0.62} \mathrm{~s}^{0.22}$, with an $R$-square value of 0.9957 and a standard error of $2.2208 \mathrm{~kJ} / \mathrm{kg}$, showing good agreement between the predicted and calculated variations in $Q_{\mathrm{m}}$, as shown in Fig. 13.

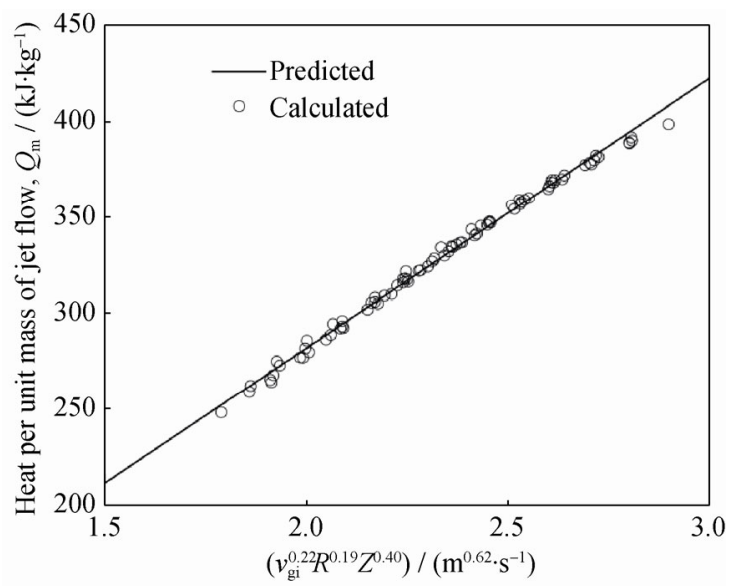

Fig. 13. Comparison between the predicted and calculated $Q_{\mathrm{m}}$ values.

Substituting Eq. (22) into Eq. (18) gives

$C_{1} \Delta T+\Delta H_{\mathrm{f}} f_{\mathrm{s}}+C_{\mathrm{d}}\left(T_{1}-T_{\text {surface }}\right)=A v_{\mathrm{gi}}^{0.22} R^{0.19} Z^{0.40}$

According to the equivalent specific heat method and heat balance,

$C_{\mathrm{d}}\left(T_{1}-T_{\text {surface }}\right)+\Delta H_{\mathrm{f}} f_{\mathrm{s}}=C_{\text {equ }}\left(T_{1}-T_{\text {surface }}\right)$

Substituting $C_{\text {equ }}=C_{\mathrm{d}}+\Delta H_{\mathrm{f}} /\left(T_{1}-T_{\mathrm{m}}\right)$ into Eq. (24) gives

$\left(T_{1}-T_{\text {surface }}\right)=\left(T_{1}-T_{\mathrm{m}}\right) f_{\mathrm{s}}$

Substituting Eq. (25) into Eq. (23) gives 
$f_{\mathrm{s}}=\frac{A}{\Delta H_{\mathrm{f}}+\left(T_{1}-T_{\mathrm{m}}\right) C_{\mathrm{d}}} v_{\mathrm{gi}}^{0.22} R^{0.19} Z^{0.40}-\frac{C_{\mathrm{l}}}{\Delta H_{\mathrm{f}}+\left(T_{1}-T_{\mathrm{m}}\right) C_{\mathrm{d}}} \Delta T$

Assuming that

$$
\begin{aligned}
& A_{1}=A /\left[\Delta H_{\mathrm{f}}+\left(T_{1}-T_{m}\right) C_{d}\right] \\
& A_{2}=C_{l} /\left[\Delta H_{\mathrm{f}}+\left(T_{1}-T_{m}\right) C_{d}\right]
\end{aligned}
$$

then,

$f_{\mathrm{s}}=A_{1} v_{\mathrm{gi}}^{0.22} R^{0.19} Z^{0.40}-A_{2} \Delta T$

It can be calculated by substituting the values of $A, \Delta H_{\mathrm{f}}$, $T_{1}, T_{\mathrm{m}}$, and $C_{\mathrm{d}}$ into Eqs. (27) and (28) that $A_{1}=0.3970$ $\mathrm{m}^{-0.62} \mathrm{~s}^{0.22}$ and $A_{2}=2.039 \times 10^{-3} \mathrm{~K}^{-1}$. Substituting all of the points plotted in Fig. 4 into Eq. (29) gives the maximum difference of 0.1025 between the $f_{\mathrm{s}}$ value predicted by Eq. (29) and the $f_{\mathrm{s}}$ value calculated using the model. The main sources of the error are the assumption that the physical properties of the alloy do not change with temperature and the use of the equivalent specific heat method.

Also, the best-fit values of $A_{1}$ and $A_{2}, 0.3449 \mathrm{~m}^{-0.62} \mathrm{~s}^{0.22}$ and $1.067 \times 10^{-3} \mathrm{~K}^{-1}$, respectively, were calculated on the basis of the points in Fig. 4, with an $R$-square of 0.9759 and a standard error of 0.0116 . The maximum difference between the $f_{\mathrm{s}}$ value predicted by Eq. (29) and the $f_{\mathrm{s}}$ value calculated by the numerical model was reduced to 0.0371 , which means the predicted $f_{\mathrm{s}}$ shows a good agreement with the values calculated using the established numerical model.

On the basis of the heat balance in Eqs. (16) and (18), Eq. (29) builds a direct relationship between the variations of the jet-flow solid fraction and the process parameters $v_{\mathrm{gi}}, R, Z$, and $\Delta T$, which can be used to conveniently and rapidly predict the
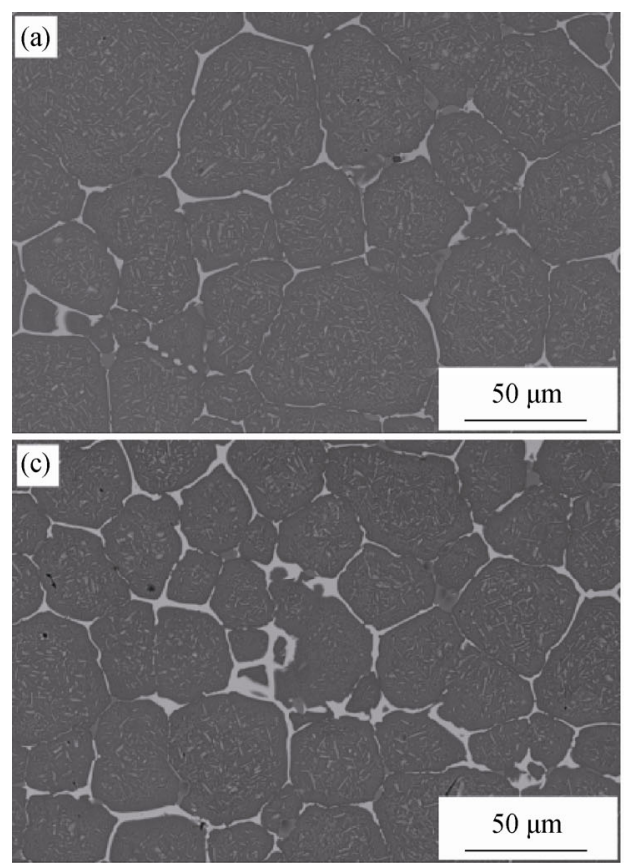

jet-flow solid fraction according to the process parameters.

Eq. (29) can contribute to the optimization of production parameters. Fig. 14(a) shows the spray-formed billet with a rippled surface. According to Eq. (29), the surface solid fraction was $65.83 \%$, which is a bit lower than the optimal solid fraction of $70 \%$. Therefore, the parameters should be optimized to increase the solid fraction. When the superheat degree was lowered from 150 to $100 \mathrm{~K}$, the solid fraction became $71.16 \%$ according to Eq. (29), which is similar to the optimal value. The spray-formed billets prepared under the optimized parameters exhibited good shapes, as shown in Fig. 14(b).

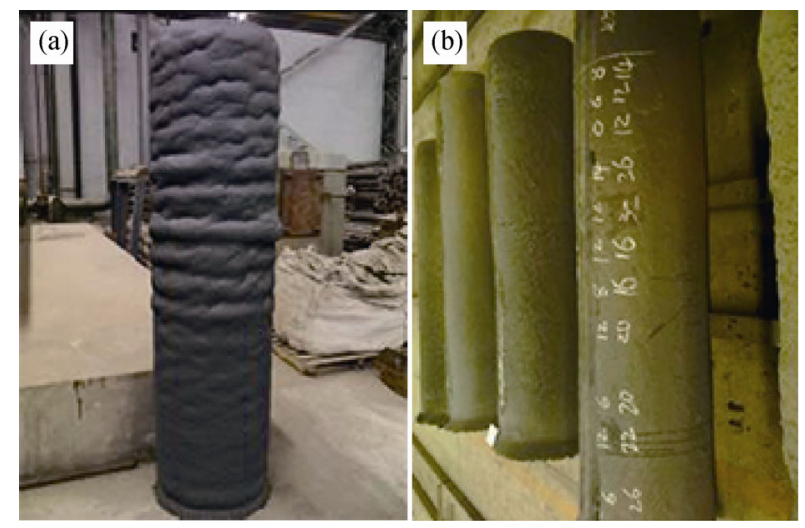

Fig. 14. Spray-formed high-speed steel billets with different superheat degrees $\left(R=0.55, v_{\mathrm{gi}}=300 \mathrm{~m} / \mathrm{s}\right.$, and $\left.Z=0.5 \mathrm{~m}\right):($ a) $\Delta T$ $=150 \mathrm{~K}$; (b) $\Delta T=100 \mathrm{~K}$.

As shown in Fig. 15(a), the solid fraction was $76.51 \%$ according to Eq. (29), which is higher than the optimal solid fraction of $70 \%$, which means a lack of liquid alloy for carbide precipitation. However, when the initial gas velocity

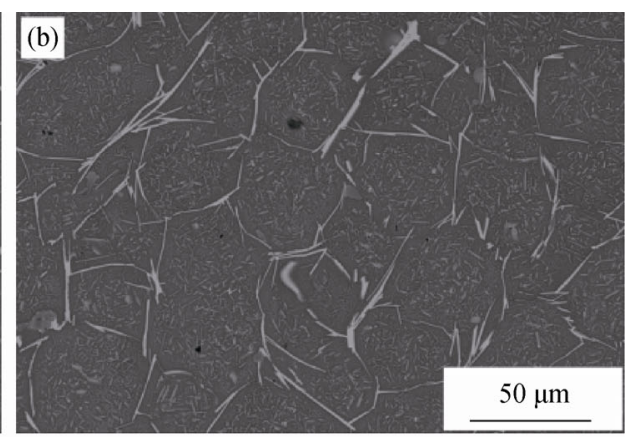

Fig. 15. Microstructures of the high-speed steel billets spray-formed with different initial gas velocities $(R=0.55, \Delta T=100 \mathrm{~K}$, and $Z=0.5 \mathrm{~m}$ ): (a) $v_{\mathrm{gi}}=400 \mathrm{~m} / \mathrm{s}$; (b) $v_{\mathrm{gi}}=300$ $\mathrm{m} / \mathrm{s} ;$ (c) $v_{\mathrm{gi}}=200 \mathrm{~m} / \mathrm{s}$. 
was changed to $200 \mathrm{~m} / \mathrm{s}$, the solid fraction became $64.18 \%$ according to Eq. (29), which means that excessive liquid alloy not only leads to the growth of carbides, but also may result in a rippled surface, as shown in Fig. 15(c). When the initial gas velocity was changed to $300 \mathrm{~m} / \mathrm{s}$, the solid fraction was $71.16 \%$ according to Eq. (29), which is close to the optimal value. The carbides present a thin network distribution in the billet, as shown in Fig. 15(b).

In conclusion, Eq. (29) is useful in optimizing the production parameters by comparing the calculated solid fraction to the optimal value. When the calculated value is close to the optimal value, the billet may have good shape and fine microstructure.

\section{Conclusions}

The motion and cooling processes of individual droplets and the jet-flow solid fraction of spray-formed W18Cr4V high-speed steel were investigated using the established numerical model. The following conclusions were drawn from the discussion:

(1) A numerical model has been established to describe the motion and thermal behaviors of droplets and to calculate the jet-flow solid fraction.

(2) An equation to predict the jet-flow solid fraction $f_{\mathrm{s}}$ according to process parameters, including the gas initial velocity $v_{\text {gi }}$, gas-to-metal mass flow rate ratio $R$, deposition distance $Z$, and superheat degree $\Delta T$, has been established on the basis of heat balance:

$$
f_{\mathrm{s}}=A_{1} v_{\mathrm{gi}}^{0.22} R^{0.19} Z^{0.40}-A_{2} \Delta T,
$$

where the best-fit values are $A_{1}=0.3449 \mathrm{~m}^{-0.62} \mathrm{~s}^{0.22}$ and $A_{2}=$ $1.067 \times 10^{-3} \mathrm{~K}^{-1}$, with an $R$-square of 0.9759 . The $f_{\mathrm{s}}$ values predicted by Eq. (29) show a reasonably good agreement with the calculated values.

(3) Eq. (29) can be used to predict the jet-flow solid fraction directly and conveniently according to the process parameters, which saves time and costs and will be a great aid in the manufacturing process.

\section{Acknowledgements}

This work was financially supported by the National High-Tech Research and Development Program of China (No. 2012AA03A509) and the National Natural Science Foundation of China (No. 51204015).

Open Access This article is distributed under the terms of the Creative Commons Attribution 4.0 International License (http://creativecommons.org/licenses/by/4.0/), which per- mits unrestricted use, distribution, and reproduction in any medium, provided you give appropriate credit to the original author(s) and the source, provide a link to the Creative Commons license, and indicate if changes were made.

\section{References}

[1] R.A. Mesquita and C.A. Barbosa, Spray forming high speed steel-properties and processing, Mater. Sci. Eng. A, 383(2004), No. 1, p. 87.

[2] A. Schulz, V. Uhlenwinkel, C. Escher, R. Kohlmannc, A. Kulmburgd, M.C. Monteroe, R. Rabitschf, W. Schützenhöferf, D. Stocchig, and D. Vialeh, Opportunities and challenges of spray forming high-alloyed steels, Mater. Sci. Eng. A, 477(2008), No. 1-2, p. 69.

[3] G.Q. Zhang, H. Yuan, D.L. Jiao, Z. Li, Y. Zhang, and Z.W. Liu, Microstructure evolution and mechanical properties of T15 high speed steel prepared by twin-atomiser spray forming and thermo-mechanical processing, Mater. Sci. Eng. A, 558(2012), p. 566.

[4] Y. Xu, C.C. Ge, and Q. Shu, Microstructure, tensile properties and heat treatment process of spray formed FGH95 superalloy, J. Iron Steel Res. Int., 20(2013), No. 4, p. 59.

[5] H.A. Godinho, A.L.R. Beletati, E.J. Giordano, and C. Bolfarini, Microstructure and mechanical properties of a spray formed and extruded AA7050 recycled alloy, J. Alloys Compd., 586(2014), Suppl.1, p. 139.

[6] Y.D. Jia, F.Y. Cao, S. Scudino, P. Ma, H.C. Li, L. Yu, J. Eckert, and J.F. Sun, Microstructure and thermal expansion behavior of spray-deposited Al-50Si, Mater. Des., 57(2014), p. 585.

[7] R.D. Cava, C. Bolfarini, C.S. Kiminami, E.M. Mazzer, W.J.B. Filho, P. Gargarella, and J. Eckert, Spray forming of $\mathrm{Cu}-11.85 \mathrm{Al}-3.2 \mathrm{Ni}-3 \mathrm{Mn}$ (wt $\%)$ shape memory alloy, $J$. Alloys Compd., 615(2014), suppl.1, p. 602.

[8] P.S. Grant, B. Cantor, and L. Katgerman, Modelling of droplet dynamic and thermal histories during spray forming: I. Individual droplet behaviour, Acta Metall. Mater., 41(1993), No. 11, p. 3097.

[9] P.S. Grant, B. Cantor, and L. Katgerman, Modelling of droplet dynamic and thermal histories during spray forming: II. Effect of process parameters, Acta Metall. Mater., 41(1993), No. 11, p. 3109.

[10] P.S. Grant and B. Cantor, Modelling of droplet dynamic and thermal histories during spray forming: III. Analysis of spray solid fraction, Acta Metall. Mater., 43(1995), No. 3, p. 913.

[11] J. Mi and P.S. Grant, Modelling the shape and thermal dynamics of Ni superalloy rings during spray forming: Part 1 . Shape modeling-Droplet deposition, splashing and redeposition, Acta Mater., 56(2008), No. 7, p. 1588.

[12] J. Mi and P.S. Grant, Modelling the shape and thermal dynamics of Ni superalloy rings during spray forming: Part 2. Thermal modelling-Heat flow and solidification, Acta Mater., 56(2008), No. 7, p. 1597.

[13] W.D. Cai and E.J. Lavernia, Modeling of porosity during 
spray forming: Part I. Effects of processing parameters, Metall. Mater. Trans. B, 29(1998), No. 5, p. 1085.

[14] W.D. Cai and E.J. Lavernia, Modeling of porosity during spray forming: Part II. Effects of atomization gas chemistry and alloy compositions, Metall. Mater. Trans. B, 29(1998), No. 5, p. 1097.

[15] S. Kang and D.H. Chang, Modelling of billet shapes in spray forming using a scanning atomizer, Mater. Sci. Eng. A, 260(1999), No. 1-2, p. 161.

[16] J.H. Hattel, N.H. Pryds, and T.B. Pedersen, An integrated numerical model for the prediction of Gaussian and billet shapes, Mater. Sci. Eng. A, 383(2004), No. 12, p. 184.

[17] C.S. Cui and A. Schulz, Modeling and simulation of spray forming of clad deposits with graded interface using two scanning gas atomizers, Metall. Mater. Trans. B, 44(2013), No. 4, p. 1030.

[18] J. Mi, P.S. Grant, U. Fritsching, O. Belkessam, I. Garmendia, and A. Landaberea, Multiphysics modelling of the spray forming process, Mater. Sci. Eng. A, 477(2008), No. 1-2, p. 2.

[19] X. Jiang, G.A. Siamas, K. Jagus, and T.G. Karayiannis, Physical modelling and advanced simulations of gas-liquid two-phase jet flows in atomization and sprays, Prog. Energy Combust. Sci., 36(2010), No. 2, p. 131.
[20] J. Gao, S.W. Park, Y. Wang, R.D. Reitza, S. Moon, and K. Nishida, Simulation and analysis of group-hole nozzle sprays using a gas jet superposition model, Fuel, 89(2010), No. 12, p. 3758.

[21] J. Du and Z.Y. Wei, Numerical analysis of pileup process in metal microdroplet deposition manufacture, Int. J. Therm. Sci., 96(2015), p. 35.

[22] Q.Q. Lu, J.R. Fontaine, and G. Aubertin, Numerical study of the solid particle motion in grid-generated turbulent flows, Int. J. Heat Mass Transfer, 36(1993), No. 1, p. 79.

[23] E.S. Lee and S. Ahn, Solidification progress and heat transfer analysis of gas-atomized alloy droplets during spray forming, Acta Metall. Mater., 42(1994), No. 9, p. 3231.

[24] P. Mathur, D. Apelian, and A. Lawley, Analysis of the spray deposition process, Acta Metall., 37(1989), No. 2, p. 429.

[25] C.G. Levi and R. Mehrabian, Heat flow during rapid solidification of undercooled metal droplets, Metall. Trans. A., 13(1982), No. 2, p. 221.

[26] J.E. Smith and M.L. Jordan, Mathematical and graphical interpretation of the log-normal law for particle size distribution analysis, J. Colloid Sci., 19(1964), No. 6, p. 549.

[27] H. Lubanska, Correlation of spray ring data for gas atomization of liquid metals, JOM, 22(1970), No. 2, p. 45. 